\title{
A Simple and Rapid Procedure for the Detection of Self-Compatible Individuals in Japanese Apricot (Prunus mume Sieb. et Zucc.) Using the Loop-Mediated Isothermal Amplification (LAMP) Method
}

\author{
Tsuyoshi Habu, ${ }^{1}$ Fumio Kishida, Miki Morikita, Akira Kitajima, \\ and Toshiaki Yamada \\ Experimental Farm, Graduate School of Agriculture, Kyoto University, \\ Osaka 569-0096, Japan
}

\section{Ryutaro Tao}

Laboratory of Pomology, Graduate School of Agriculture, Kyoto University, Kyoto 606-8502, Japan

Additional index words. Japanese apricot, self-compatibility, marker-assisted selection, loop-mediated isothermal amplification

Abstract. Japanese apricot (Prunus mume Sieb. et Zucc.) exhibits S-RNase-based gametophytic self-incompatibility as do other Prunus species. Both self-incompatible and self-compatible Japanese apricot cultivars are grown commercially in Japan. These self-compatible cultivars are shown to have a common $S$-haplotype called $S^{f}$ that contains $S^{f}$-RNase and $S F B^{f}$ ( $S$-haplotype-specific F-box protein). This study describes a simple and rapid detection of $S F B^{f}$, in Japanese apricot, based on loop-mediated isothermal amplification (LAMP) method. A set of 4 primers, F3, B3, FIP, and BIP primer, were designed from the exon and the putative inserted sequence of $S F B^{f}$. Optimal reaction time at $63{ }^{\circ} \mathrm{C}$ was determined to be 90 minutes. It appeared that the LAMP method combined with the ultrasimple DNA extraction efficiently detected $S F B^{f}$. The advantage of the marker-assisted selection of self-compatibility based on the LAMP method was discussed.

Japanese apricot exhibits S-RNase-based gametophytic self-incompatibility, as do other self-incompatible crops in the Rosaceae (Janick and Moore, 1975; Miyake et al., 1995; Yaegaki et al., 2001). The specificity of the self-incompatibility response is determined by the $S$-haplotypes of the polymorphic $S$ locus. The self-incompatible phenotypes of the pistil and pollen are controlled by $S$ locus genes, called the pistil determinant $S$-RNase, and the pollen determinant SFB (Entani et al., 2003, Ushijima et al., 2003, 2004; Yamane et al., 2003a, 2003b), respectively.

Although both self-incompatible and selfcompatible Japanese apricot cultivars are grown commercially in Japan, self-compatible cultivars have a horticultural advantage because no cross-pollinizer is required. Consequently, one of the major breeding goals for Japanese apricot is to produce self-compatible cultivars. However, assessment of selfcompatibility, as determined by conventional methods of pollination and pollen-tube

Received for publication 16 Jan. 2006. Accepted for publication 6 Apr. 2006

${ }^{1}$ To whom reprints requests should be addressed. e-mail habu@kais.kyoto-u.ac.jp. growth test, usually requires several years after the tree reaches the flowering age. With marker-assisted selection for self-compatibility, the time required for breeding of selfcompatible Japanese apricot cultivars could be considerably shortened because molecular markers make it possible to select selfcompatible individuals soon after germination.

Previously, Tao et al. $(2000,2002)$ found that self-compatible cultivars of Japanese apricot share a common $S$-haplotype, termed $S$-haplotpe, that can be used as a molecular marker for self-compatibility. Furthermore, to detect the self-compatible individuals easily, Tao et al. (2003) developed a polymerase chain reaction (PCR) primer set, Ken2 and PM-R, from the intron sequence of $S^{f}-R$ Nase, which can be used to specifically amplify the $S^{f}$-RNase fragment. However, Ushijima et al. (2004) recently found that an insertion into the $S F B^{f}$ could be a primary cause of the selfcompatibility in Japanese apricot cultivars with the $S$-haplotype. Although $S$-RNase and $S F B$ are tightly linked to each other as if they were a single gene and $S^{f}$-RNase can be a good marker for self-compatibility, the use of a molecular marker for the mutated $S F B^{f}$ would be a more direct way. Yamane et al. (2003b) developed a method based on
DNA gel blot analysis to detect $S F B^{f}$. However, several bands from the homologous DNA sequences to $S F B$ made the detection of $S F B^{f}$ difficult.

A novel nucleic acid amplification method, termed loop-mediated isothermal amplification (LAMP), has recently been reported by Notomi et al. (2000). The LAMP method is capable of amplifying DNA under isothermal conditions with high specificity and speed. An important advantage of LAMP is its ability to amplify specific sequences of DNA under isothermal conditions between 63 and $65^{\circ} \mathrm{C}$. In addition, LAMP can be easily judged from turbidity of the reaction mixture by the naked eye without electrophoresis. These features allow the method to be performed simply compared with PCR, which uses complicated equipment such as thermal cycling machines and electrophoresis apparatus. In this study, we established a LAMP-based protocol and examined its reliability in the detection of self-compatible progenies with $S F B^{f}$. We also tested several different miniprep methods for plant DNA isolation to be used for LAMP.

\section{Materials and Methods}

\section{Plant materials}

Six self-incompatible Japanese apricot cultivars ('Gessekai', 'Nanko', 'Gyokuei', 'Ousyuku', 'Kotsubu-Nanko', and 'KairyoUchidaume') and 8 self-compatible cultivars ('Rinsyu', 'Shinpeidayu', 'Jizo-ume', 'Ryukyo-Koume', 'Benisashi', 'Oriheme', 'Hachiro', and 'Kensaki') were used in this study.

\section{DNA extraction}

Total DNAs were extracted from young leaves of 14 cultivars by the CTAB method described by Doyle and Doyle (1987), the miniprep method by Edwards et al. (1991), and the ultrasimple DNA extraction method by Ikeda et al. (2001).

\section{LAMP reaction}

The LAMP reaction was conducted as described by Notomi et al. (2000). LAMP requires a set of 4 primers (B3, F3, FIP, and BIP), recognizing a total of 6 distinct sequences within target DNA. Primers for LAMP were designed using Primer Explorer V3 software on the web site of "Netlaboratory" (http://primerexplore.jp; FUJITSU, Japan) targeting the exon and the putative inserted sequence of $S F B^{f}$ (Fig. 1, Table 1). Primer $\mathrm{BIP}$ consisted of the $\mathrm{B} 1$ direct sequence and the B2 complementary sequence. Primer FIP consisted of the F1 complementary sequence and the F2 direct sequence. Primer F3 and B3 were located outside the $\mathrm{F} 2$ and $\mathrm{B} 2$ regions, respectively.

LAMP reactions were carried out using Loopamp Kit (Eiken Chemical, Tokyo, Japan). Reaction mixture $(25 \mu \mathrm{L})$ contained 40 pmole of FIP and BIP, 5 pmole of F3 and B3, $12.5 \mu \mathrm{L}$ of $2 \times$ reaction mixture $(40 \mathrm{mM}$ Tris- $\mathrm{HCl}[\mathrm{pH} 8.8], 20 \mathrm{mM} \mathrm{KCl}, 16 \mathrm{mM}$ $\mathrm{MgSO}_{4}, 20 \mathrm{mM}\left[\mathrm{NH}_{4}\right]_{2} \mathrm{SO}_{4}, 0.2 \%$ Tween 

F1 B1

525

592
$\mathrm{B} 2$

GCGCACCAAGAAGACAAGATATACGTGGTTCACCCTTAATGAATGGGCTACGTCCACGGAGAAGTA B3

TGTTCTCATTATAATAGTGTATGATTACATTTGTACATGGgGTTGGACCCGAATATAAAGATAACAAGT

Fig. 1. Partial nucleotide sequence of $S F B^{f}$ used to design LAMP primers. The putative inserted sequence is shown by box (Ushijima et al., 2004). An asterisk indicates stop codon and underlines indicate the positions of the targeting sequences.

Table 1. Primer sequences used in this study.

\begin{tabular}{ll}
\hline Primer & \multicolumn{1}{c}{ Nucleotide sequence } \\
\hline F3 & GTTCATGCAATGGTTTAGTTTG \\
B3 & CACGTATATCTTGTCTTCTTGG \\
FIP & GGTCTTAAATTTCCTAACCGATGGGGATGAGATATTAGAATCTCGAAAG \\
BIP & TAAGCACCAACATCATCAAATTTGGCCTTACAGCCTTGTAGTCATT \\
\hline
\end{tabular}

20, $1.6 \mathrm{M}$ betain, $2.8 \mathrm{mM}$ of each deoxynucleotide triphosphate [dNTP]), Bst DNA polymerase, and $2 \mu \mathrm{L}$ of the DNA template. The mixture was incubated at $63{ }^{\circ} \mathrm{C}$ for 30 , 60,90 and 120 minutes and then at $80^{\circ} \mathrm{C}$ for 2 minutes to end the reaction. A total of $5 \mu \mathrm{L}$ of the product was analyzed in $1 \%$ agarose gel by electrophoresis, stained with ethidium bromide, and visualized by ultraviolet transillumination. Furthermore, because the LAMP produces a large amount of byproduct, a pyrophosphate ion, yielding a white precipitation of magnesium pyrophosphate in the LAMP reaction mixture, the observation of the turbidity of the reaction mixture was also used for the detection of $S F B^{f}$.

\section{Results}

\section{Determination of reaction time for the detection of $S F B f$ by LAMP}

The LAMP reaction was carried out using the genomic DNA isolated from a selfcompatible cultivar, 'Ryukyo-Koume,' to optimize the conditions. It appeared that 90

Fig. 2. Determination of the optimal LAMP reaction time for detection of $S F B^{f}$ by (A) gel electrophoresis and (B) turbidity. M: DNA size marker (123-bp ladder), lanes 30, 60, 90, 120: LAMP reaction carried out for $30,60,90,120$ minutes, respectively.

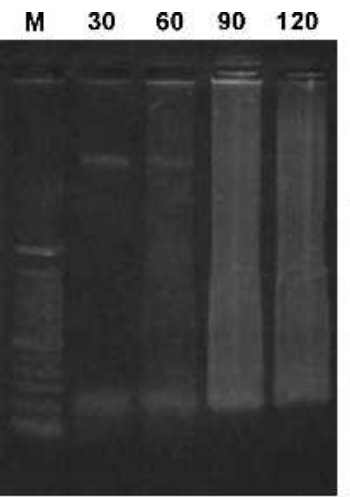

A

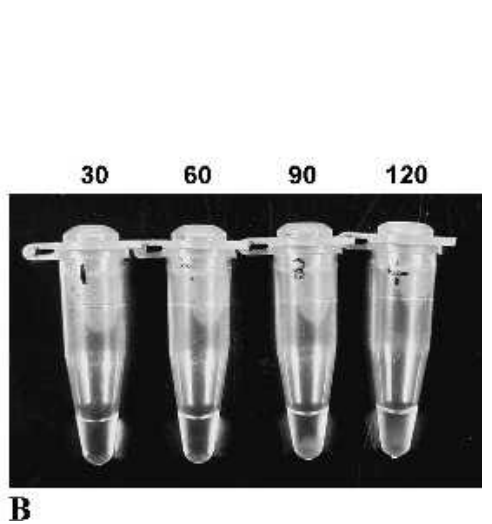

B

minutes of incubation at $63^{\circ} \mathrm{C}$ was enough to detect $S F B^{f}$. Less amplification and no turbidity in tubes were found at 30 minutes and 60 minutes, whereas the specific DNA banding patterns on the gel and the white turbidity in tubes were seen at 90 minutes and 120 minutes (Fig. 2A, B).

\section{Optimal DNA extraction method for the detection of $S F B f$ by LAMP}

The genomic DNAs isolated from a selfcompatible cultivars 'Ryukyo-Koume' by 3 DNA extraction methods were used for the LAMP reaction. DNA isolated by the CTAB method and the ultrasimple DNA extraction method yielded almost the same amount of LAMP products and more than that obtained by the miniprep method described by Edwards et al. (1991) (Fig. 3). The shortening and simplification of the DNA extraction step is also important to save time and labor for the selection of selfcompatible individuals from hundreds of seedlings. Therefore, the ultrasimple DNA extraction method (Ikeda et al., 2001), which can be carried out within 30 minutes, was suitable for the selection by LAMP. DNA isolated by the CTAB method was also good for the LAMP reaction of $S F B^{f}$; however, the CTAB method takes few hours and requires many steps with many reagents and equipments.

Detection of self-compatibility by LAMP

The optimized LAMP procedure for the detection of $S F B^{f}$ was tested to determine if the self-compatible cultivars could be distinguished from the self-incompatible ones. The specific DNA banding patterns from the LAMP products and the white precipitation

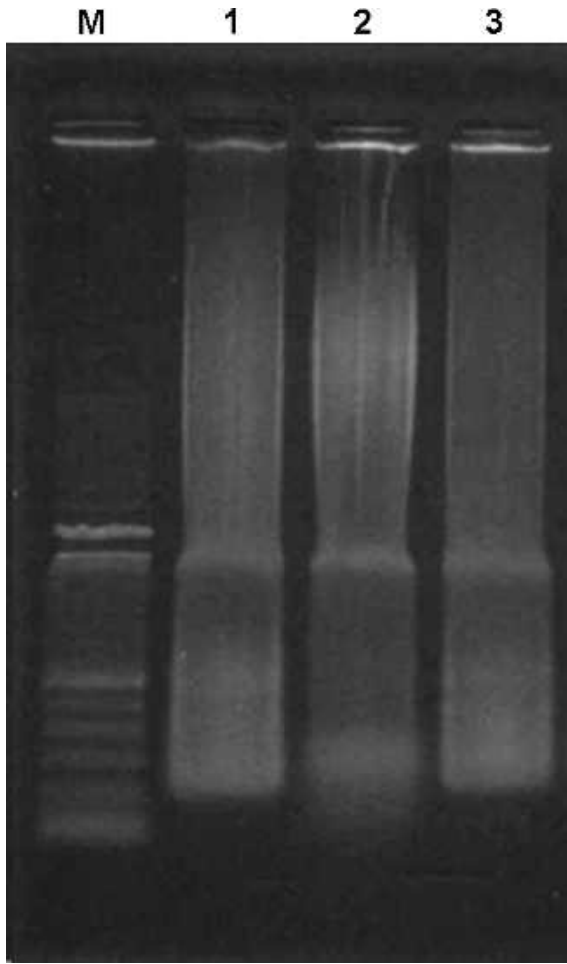

Fig. 3. Detection of $S F B^{f}$ by LAMP with 3 different DNA extraction methods. M: DNA size marker (123-bp ladder), lane 1: the CTAB method (Doyle and Doyle, 1987), lane 2: the miniprep method (Edwards et al., 1991), lane 3: the ultrasimple DNA extraction method (Ikeda et al., 2001).

of magnesium pyrophosphate were detected only in the self-compatible cultivars (Fig. 4A, B). Thus, we concluded that the LAMP reaction occurred specific to $S F B^{f}$ in the self-compatible cultivars of Japanese apricot and that this procedure could be applied to the selection of self-compatible individuals with the $S^{f}$-haplotype.

\section{Discussion}

Marker-assisted selection permits the rapid identification of key individuals harboring useful genes. Thus far, PCR is the most widely used nucleic acid amplification method for the marker-assisted selection because of its apparent simplicity and consistency. However, the LAMP technique has the following favorable characteristics that give it an advantage over other nucleic acidbased techniques, including PCR. First, because the LAMP method amplifies nucleic acid in isothermal conditions in the range of 63 to $65{ }^{\circ} \mathrm{C}$, it only requires simple reaction equipment. Second, the amplification efficiency is extremely high because there is no time loss resulting from thermal change, and inhibition reactions at the later stage of amplification is less likely to occur compared with PCR. Third, because the LAMP method uses 4 primers recognizing 6 distinct regions on the target DNA sequence, its specificity is extremely high. Finally, because the LAMP 


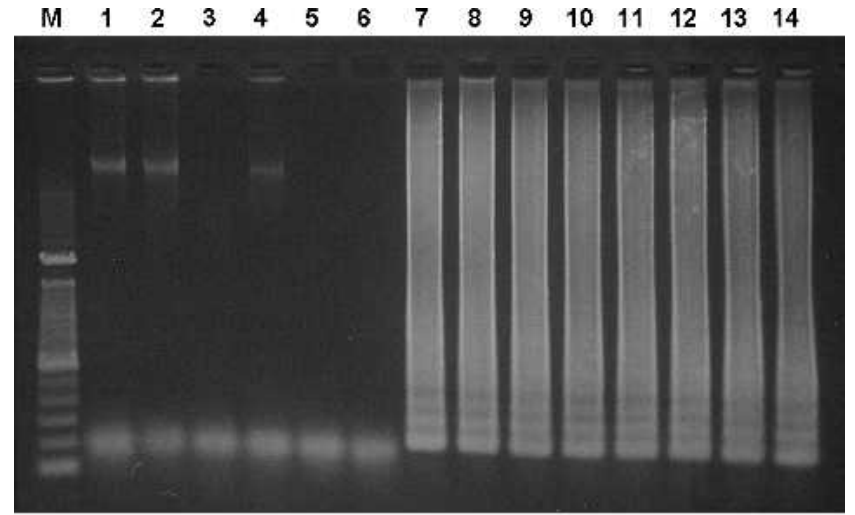

$\mathbf{A}$

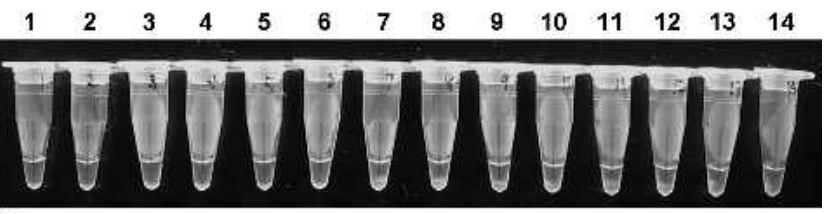

B

Fig. 4. Detection of $S F B^{f}$ by LAMP from selfincompatible and self-compatible cultivars by (A) gel electrophoresis and (B) turbidity. M: DNA size marker (123-bp ladder), lane 1: 'Gessekai', lane 2: 'Nanko', lane 3: 'Gyokuei', lane 4: 'Ousyuku', lane 5: 'Kotsubu-Nanko', lane 6: 'Kairyo-Uchidaume', lane 7: 'Rinsyu', lane 8: 'Shinpeidayu', lane 9: 'Jizo-ume', lane 10: 'RyukyoKoume', lane 11: 'Benisashi', lane 12: 'Oriheme', lane 13: 'Hachiro', lane 14: 'Kensaki', lanes 16: self-incompatible cultivars, and lanes 7-14: self-compatible cultivars.

method has high ability to synthesize an extremely large amount of amplification products, a large amount of byproduct, a pyrophosphate ion, is also produced yielding a white precipitation of magnesium pyrophosphate in the LAMP reaction mixture. Thus, the measurement or the observation of the turbidity of the reaction mixture allows easy detection of amplification of target DNA. Hence, the LAMP method can be a useful tool for the marker-assisted selection.

In this study, the LAMP method combined with the 3 DNA extraction methods was tested to detect self-compatible individuals of Japanese apricot. The optimal reaction time at $63{ }^{\circ} \mathrm{C}$ for detection of $S F B^{f}$ by LAMP was 90 minutes and the most suitable DNA extraction method was the ultrasimple DNA extraction method described by Ikeda et al. (2001). When the reaction was performed with these optimized procedures, the specific DNA banding patterns of the LAMP products were detected only in the self-compatible cultivars of Japanese apricot. Although a single nonspecific band was observed in self-incompatible cultivars of 'Gessekai', 'Nanko', and 'Ousyuku', it could be easily distinguished from the LAMP products from $S F B^{f}$. The single band could be amplified products from $S F B^{l}$ by inner primers FIP and BIP because these 3 cultivars shared the $S^{l}$-haplotype. In addition to the extreme difference in the banding pattern, turbidity of the reaction mixture could be used as a good indication for the LAMP reaction from $S F B^{f}$.

In conclusion, we have developed a simple, rapid, and highly specific procedure for the selection of self-compatible individuals with $S$-haplotype. Because this method can be carried out in a short time with very simple equipments, it would serve as a very useful tool for breeding of self-compatible cultivars in the Japanese apricot.

\section{Literature Cited}

Doyle, J.I. and J.L. Doyle. 1987. A rapid DNA isolation procedure for small quantities of fresh leaf tissue. Phytochem. Bull. 19:11-15.

Edwards, K., C. Johnstone, and C. Thompson. 1991. A simple and rapid method for the preparation of plant genomic DNA for PCR analysis. Nucleic Acids Res. 19:1349.

Entani, T., M. Iwano, H. Shiba, F.-S. Che, A Isogai, and S. Takayama. 2003. Comparative analysis of the self-incompatibility $(S$-) locus region of Prunus mume: identification of a pollen-expressed F-box gene with allelic diversity. Genes Cells 8:203-213.
Ikeda, N., N.S. Bautista, T. Yamada, O. Kamijima and T. Ishii. 2001. Ultra-simple DNA extraction method for marker-assisted selection using microsatellite markers in rice. Plant Mol. Biol. Rep. 19:27-32.

Janick, J. and J.N. Moore. 1975. Advances in fruit breeding. Purdue Univ. Press. W. Lafayette, Ind.

Miyake, M., M. Yamaguchi, and T. Haji. 1995. The self-compatibility in mume cultivars. J. Japan [in Japanese]. Soc. Hort. Sci. 64(suppl. 2)116-1117.

Notomi, T., H. Okayama, H. Masubuchi, T. Yonekawa, K. Watanabe, N. Amino, and T. Hase. 2000. Loop-mediated isothermal amplification of DNA, Nucleic Acids Res. 28:e63.

Tao, R., T. Habu, H. Yamane, and A. Sugiura. 2000. Molecular markers for self-compatibility in Japanese apricot (Prunus mume). HortScience 35:112-1123

Tao, R., T. Habu, A. Namba, H. Yamane, F. Fuyuhiro, K. Iwamoto, and A. Sugiura. 2002. Inheritance of $S^{f}$-RNase in Japanese apricot (Prunus mume) and its relation to self-compatibility. Theor. Appl. Genet. 105:222-228.

Tao, R., A. Namba, H. Yamane, Y. Fuyuhiro, T. Watanabe, T. Habu, and A. Sugiura. 2003. Development of the $S$-RNase gene-specific PCR primer set for Japanese apricot (Prunus mume Sieb. et Zucc.) [in Japanese]. Hort. Res. (Japan) 2:237-240

Ushijima, K., H. Sassa, A.M. Dandekar, T.M. Graziel, R. Tao, and H. Hirano. 2003. Structural and transcriptional analysis of the selfincompatibility $(S)$ locus of almond (Prunus dulcis): identification of a pollen-expressed F-box gene with haplotype-specific polymorphism. Plant Cell 15:771-781.

Ushijima, K., H. Yamane, A. Watari, E. Kakehi, K. Ikeda, N.R. Hauck, A.F. Iezzoni, and R. Tao. 2004. The $S$-haplotype-specific F-box protein gene, $S F B$, is defective in self-compatible haplotypes of Prunus avium and mume. Plant J. 39:573586.

Yaegaki, H., T. Shimada, T. Moriguchi, H. Hayama, T. Haji, and M. Yamaguchi. 2001. Molecular characterization of $S$-RNase genes and $S$-genotypes in the Japanese apricot (Prunus mume Sieb. et Zucc.). Sex. Plant Reprod. 13:251-257.

Yamane, H., K. Ikeda, K. Ushijima, H. Sassa, and R. Tao. 2003a. A pollen-expressed gene for a novel protein with an F-box motif that is very tightly linked to a gene for $S$-RNase in two species of cherry, Prunus cerasus and P. avium. Plant Cell Physiol. 44:764-769.

Yamane, H., K. Ushijima, H. Sassa, and R. Tao. $2003 \mathrm{~b}$. The use of the $S$ haplotype-specific F-box protein gene, $S F B$, as a molecular marker for $S$-haplotypes and self-compatibility in Japanese apricot (Prunus mume). Theor. Appl. Genet. 107:1357-1361. 